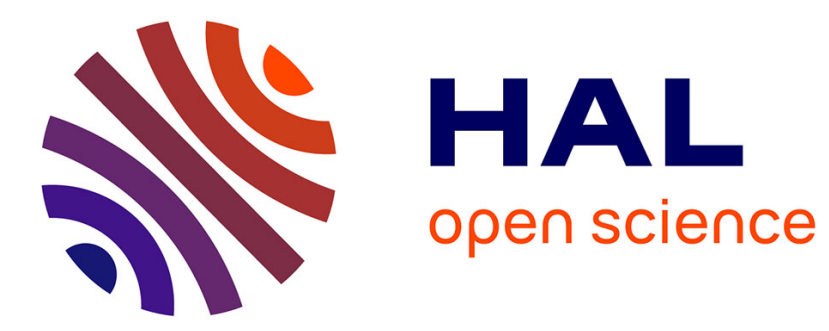

\title{
Substrate integrated waveguide (SIW) inductive window band-pass filter based on post-wall irises
}

\author{
K. Nouri, Kamel Haddadi, O. Benzaïm, T. Lasri, M. Feham
}

\section{To cite this version:}

K. Nouri, Kamel Haddadi, O. Benzaïm, T. Lasri, M. Feham. Substrate integrated waveguide (SIW) inductive window band-pass filter based on post-wall irises. European Physical Journal: Applied Physics, 2011, 53 (3), pp.33607-1-5. 10.1051/epjap/2010100057 . hal-00672781

\section{HAL Id: hal-00672781 \\ https://hal.science/hal-00672781}

Submitted on 22 Feb 2012

HAL is a multi-disciplinary open access archive for the deposit and dissemination of scientific research documents, whether they are published or not. The documents may come from teaching and research institutions in France or abroad, or from public or private research centers.
L'archive ouverte pluridisciplinaire HAL, est destinée au dépôt et à la diffusion de documents scientifiques de niveau recherche, publiés ou non, émanant des établissements d'enseignement et de recherche français ou étrangers, des laboratoires publics ou privés. 


\title{
Substrate Integrated Waveguide (SIW) inductive window band-pass filter based on post-wall irises
}

\author{
K. Nouri ${ }^{1,2}$, K. Haddadi ${ }^{2}$, O. Benzaïm ${ }^{2}$, T. Lasri ${ }^{2}$, and M. Feham ${ }^{1}$ \\ ${ }^{1}$ Laboratoire de recherche Systèmes et Technologies de l'Information et de la communication STIC, Faculté des Sciences - \\ Université de Tlemcen - BP 119 - Tlemcen, Algérie \\ ${ }^{2}$ Institut d'Electronique, de Microélectronique et de Nanotechnologie (IEMN-DHS), USTL, UMR CNRS-8520, Avenue \\ Poincaré - B.P. 60069 - 59652 Villeneuve d'Ascq Cedex - France
}

Received : 1 September 2009

Published online :

\begin{abstract}
In this article, we demonstrate a new inductive-window 5.245-GHz-band-pass filter based on post-wall irises by standard PcB process on Epoxy FR4 substrate. A new and easy to build microstrip-to-waveguide transition that consists of three tapers is also designed to connect the filter to standard measurement system. Both simulated results and measurements have shown insertion-loss lower than $5 \mathrm{~dB}$ within $14 \%$ bandwidth around $5.245 \mathrm{GHz}$ and input return loss better than $25 \mathrm{~dB}$ over the frequency range.
\end{abstract}

PACS. 41.20.-q Applied classical electromagnetism - 41.20.Jb Electromagnetic wave propagation; radiowave propagation.

\section{Introduction}

Filters are widely used in satellite and modern communication systems. General requirements for these filters are low insertion loss, high power capacity, small size and high rejection with low cost realization [1]-[2].

Rectangular waveguide components have advantages over other planar transmission structures for microwave and millimeter-wave band applications because of their low loss and high Q-factor. But their high cost and difficult integration to planar circuits prevent these components from being used in low-cost high-volume applications. Recently, a new concept of substrate integrated waveguide (SIW) technique has been proposed [3].

Many components such as antennas, power dividers, filters and diplexers, based on SIW technology have been reported [4]-[6]. This technology offers a good option for the design of microwave and millimeter-wave filters. It provides a low profile, low cost standard printed circuit boards (PCB) and low weight scheme while maintaining high performance [7]-[9].

SIW structures are realized by two bilateral walls of periodic metallic via-hole arrays in substrate and grounded planes which can be easily interconnected with other elements of the system on a single substrate platform without tuning. This system can be miniaturised into small package (called the system in package - SIP) with small size and low cost [10].

This paper presents the design and performance of a new inductive-window filter using post-wall irises operating around $5.245 \mathrm{GHz}$. We begin with a brief analysis of C-band SIW-microstrip lines. Then, a new stepped transition is proposed to connect SIW circuits to microstrip ones. The filter is designed and fabricated by using low cost printed circuit board (PCB) technology. The measurements are performed by means of a vector network analyzer (HP8720C). Electromagnetic simulations and measured responses of the filter are presented to validate the proposed approach. Compared to previous studies related to SIW filters using post-wall irises, a wide bandwidth operation of about $14 \%$ and return loss better than $25 \mathrm{~dB}$ are achieved by the proposed filter associated to stepped transitions [11]-[13]. 


\section{Integrated-Waveguide Analysis}

A substrate integrated waveguide (SIW) is made of metallic via-hole arrays in the substrate between top and bottom metal layers replacing the two metal sidewalls. A comparison between a conventional waveguide and a SIW is given in Fig. 1.

The propagation properties in the SIW and in the conventional metallic rectangular waveguide (RWG) are very similar. In particular, the electromagnetic field distribution is $\mathrm{TE}_{10}$-like [14]. Thus, the initial dimensions of the SIW resonator cavity can be determined by the conventional resonant frequency formula of metallic waveguide resonator, where the length and width of the metallic cavity, $L_{G}$ and $W_{G}$, should be replaced by the equivalent width $W$ and length $L$ of the SIW cavity because of the presence of vias sidewall.

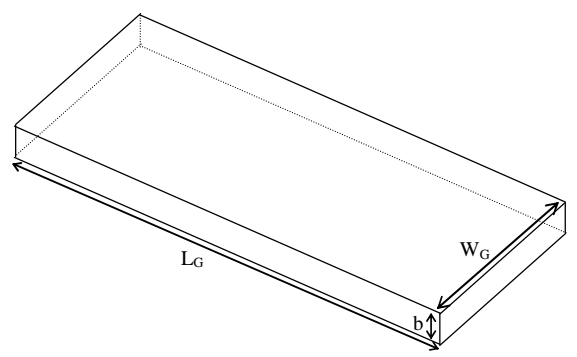

(a)

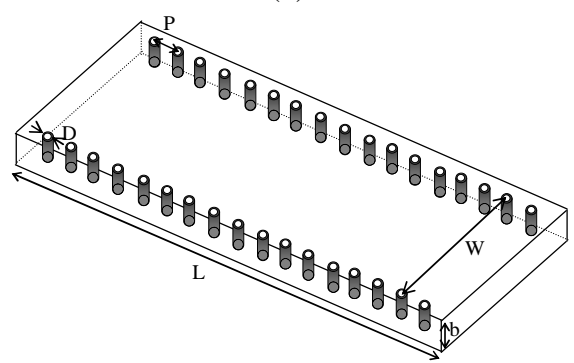

(b)

Fig.1. Configuration of the waveguides. (a) Conventional rectangular waveguide. (b) On-substrate integrated waveguide.

A SIW cavity can be designed by using the following relations $[8,14,15]$ :

$$
\begin{gathered}
L=L_{G}-\frac{D^{2}}{0.95 P} \\
W=W_{G}-\frac{D^{2}}{0.95 P}
\end{gathered}
$$

The equations (1) and (2) denote respectively the relations between the dimensions of the conventional and the SIW waveguides. The parameters $\mathrm{D}$ and $\mathrm{P}$ are the diameter and the period of via holes respectively.
We propose in this section an electromagnetic analysis of a SIW cavity at the test frequency $5.5 \mathrm{GHz}$. In comparison with conventional waveguide, the SIW is an artificial periodic waveguide. Therefore, the post-diameter D and the period P of the posts may significantly affect the propagation in the SIW and the return loss at the input ports. In order to ensure the propagation of the electric field in the synthesized waveguide section, an optimization of $\mathrm{P}$ and $\mathrm{D}$ is proposed. A full-wave finite-element method (FEM) based on a commercial software package (HFSS) is used for simulations. The top, middle, bottom and sidewall metalizations are all copper and the dielectric material is an Epoxy FR4 substrate with $\varepsilon_{r}=4.4$ and $\tan \delta=0.015$. The distance between the rows of the centers of via holes is $\mathrm{W}=19 \mathrm{~mm}$. After optimization, $\mathrm{D}$ is set to $1 \mathrm{~mm}$ and $\mathrm{P}$ to $1.8 \mathrm{~mm}$.

The figure 2 shows the electric fields distribution in the cross-sectional view in the conventional rectangular waveguide and in the SIW waveguide.

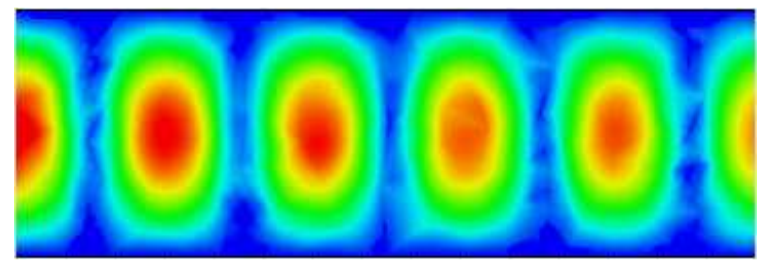

(a)

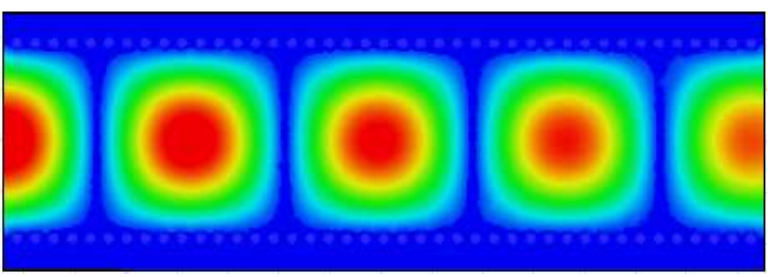

(b)

Fig.2. Electrics fields distributions in a rectangular waveguide and in a SIW. F $=5.5 \mathrm{GHz}$ (HFSS simulation). (a) RWG. (b) SIW.

From these graphs, one can note that the dominant mode of the SIW is quite similar to the $\mathrm{TE}_{10}$ mode of the conventional waveguide. The maximum field is present at the middle of the guide.

In order to perform robust S-parameters measurements of the SIW circuits, and to connect them to standard measurement equipment, a transition from microstrip to the SIW is proposed in the next part of this paper.

\section{Microstrip Stepped transition}

Many approaches have been reported for the integration of waveguides and planar circuits [7, 9, 17, 18, 19]. In this work, a new and easy to build microstrip to SIW planar stepped transition is discussed. A schematic view of a SIW with two stepped transitions is shown in Fig. 3. 


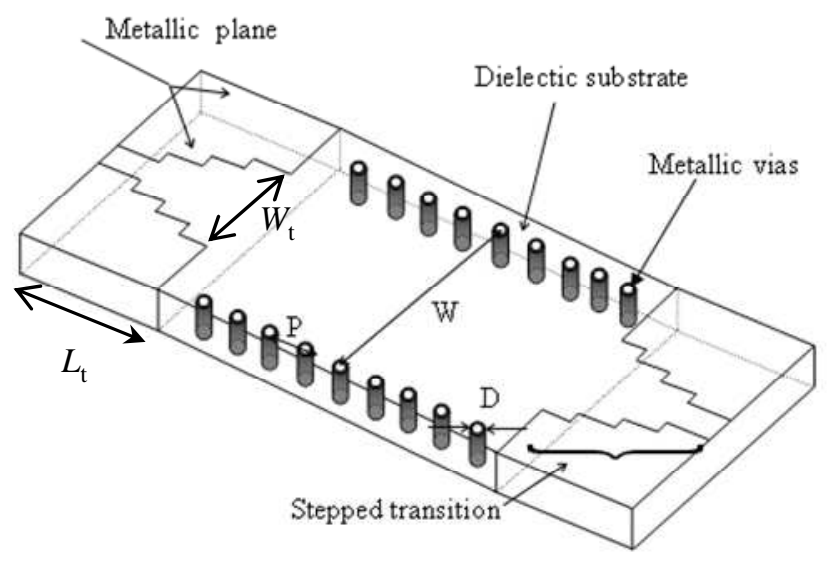

Fig.3. Topology of the SIW with two stepped transitions.

As shown in Fig. 3, the transition comprises three tapers. The dimensions of the tapers as a function of $\mathrm{L}_{\mathrm{t}}$ and $\mathrm{W}_{\mathrm{t}}$ are summarized in table 1 .

\begin{tabular}{|c|c|c|c|}
\hline Taper $\mathrm{i}$ & 1 & 2 & 3 \\
\hline Width $\mathrm{W}_{\mathrm{ti}}(\mathrm{mm})$ & $\mathrm{W}_{\mathrm{t}} / 3$ & $2 \mathrm{~W}_{\mathrm{t}} / 3$ & $\mathrm{~W}_{\mathrm{t}}$ \\
\hline Length $\mathrm{L}_{\mathrm{ti}}(\mathrm{mm})$ & $\mathrm{L}_{\mathrm{t}} / 3$ & $\mathrm{~L}_{\mathrm{t}} / 3$ & $\mathrm{~L}_{\mathrm{t}} / 3$ \\
\hline
\end{tabular}

Tab. 1. Geometric parameters of the microstrip to SIW planar stepped transition.

In order to achieve a low-loss broadband response, the transition is designed by simultaneously considering both impedance matching and field matching. Thus, due to the electric field distribution in the SIW, each transition is connected to the center of the width of the SIW, since the electric field of the fundamental mode is maximum in this place [20]. The optimization of the transition is performed by means of electromagnetic simulations by varying the dimensions $\left(\mathrm{L}_{\mathrm{t}}, \mathrm{W}_{\mathrm{t}}\right)$ of the stepped geometry. After optimization, the dimensions retained are $\mathrm{W}_{\mathrm{t}}=5.82 \mathrm{~mm}$ and $\mathrm{L}_{\mathrm{t}}=24.9 \mathrm{~mm}$.

The distribution of the electric field is given in Fig. 4.

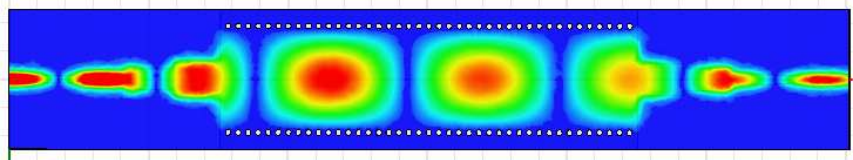

Fig.4. Electric field distribution in SIW with stepped transitions. $\mathrm{F}=5.5 \mathrm{GHz}$ (HFSS simulation).

This figure denotes a good input/output electric field matching.

The proposed SIW with stepped transitions was fabricated on a substrate of Epoxy FR4 under a standard PCB process. A photograph of the prototype is shown in Fig. 5.

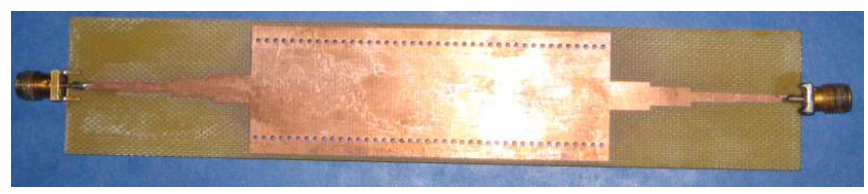

Fig.5. Photograph of the manufactured SIW with stepped transitions.

To measure the S-parameters, a SMA connector is connected to each port. The measured S-paramters are performed with a vector network analyzer (HP8720C) in the frequency band $4.4-6.8 \mathrm{GHz}$. The simulated and measured results are shown in Fig. 6.

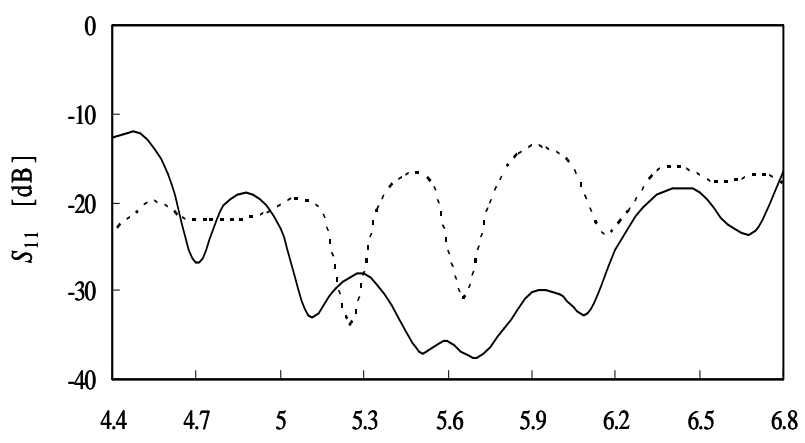

Freq. $[\mathrm{GHz}]$

(a)

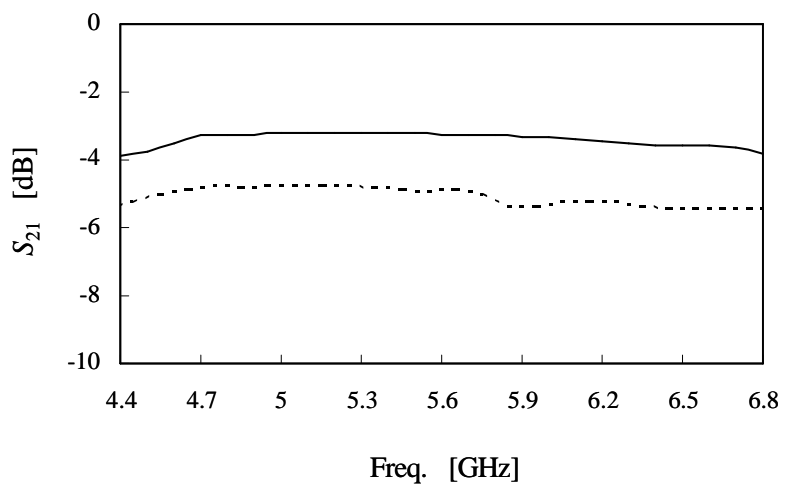

(b)

Fig.6. Simulated and measured S-parameters of the SIW with stepped transitions ( - HFSS Simulation - - Measurement ).

(a) $S_{11}$ as a function of frequency. (b) $S_{21}$ as a function of frequency.

From the figure 6-a, the measured return loss characteristics are less than $13 \mathrm{~dB}$ in the frequency range $4.4-6.8 \mathrm{GHz}$. From the figure $6-\mathrm{b}$, the measured insertion loss are around 5 $\mathrm{dB}$. The discrepancies of about $1.5 \mathrm{~dB}$ with the simulated insertion loss are mainly due to the SMA connectors that have not been taken into account in the simulation. Thus, on can conclude that these results are in good agreement with the simulated ones and validate the proposed microstrip-SIW transition.

In the last part of this work, a SIW inductive band-pass filter based on post-wall irises with stepped transitions is proposed. 


\section{SIW inductive window band-pass filter}

Filters with operation frequencies around $5 \mathrm{GHz}$ and wide bandwidths will be needed in future Wireless Local Area Network (WLAN) applications. Judging from its electrical performance, the SIW is a good compromise between the air-filled rectangular waveguide and planar circuit [21]. Therefore, a $4^{\text {rd }}$ degree SIW cavity filter with a bandwidth of $730 \mathrm{MHz}$ around $5.245 \mathrm{GHz}$ is designed and realized in this last part. The cavities of the filter using inductive post-wall irises are shown in Fig. 7.

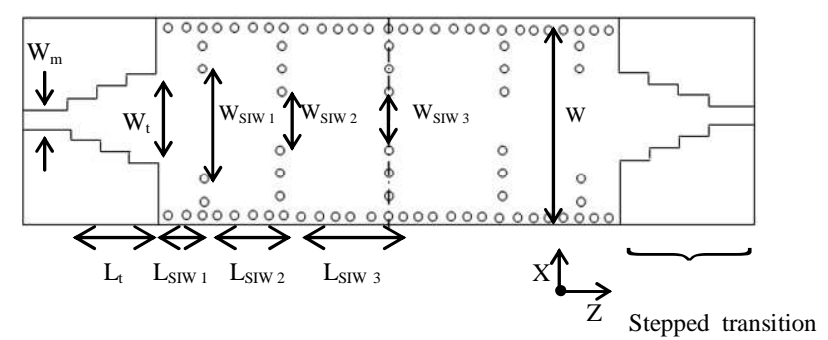

Fig. 7. Geometry of SIW inductive-window filter using post-wall irises. $\mathrm{F}=5.245 \mathrm{GHz}$.

The dimensions of the filter are selected as, $\mathrm{W}=24 \mathrm{~mm}$, $\mathrm{D}=1 \mathrm{~mm}, \mathrm{P}=2 \mathrm{~mm}$. The structure comprises four resonant cavities coupled by five metal irises (Fig. 8-a). The design revolves on the determination of the lengths $\mathrm{L}_{\text {SIWi }}(i=1, \ldots, 3)$ of the cavities and the widths $\mathrm{W}_{\mathrm{SIWi}}(\mathrm{i}=1, \ldots, 3)$ of the resonators. To that end, a general method is briefly presented to design a filter based on post wall irises. First, the integrated waveguide is mapped to a conventional rectangular waveguide using the relations (1) and (2). As illustrated in Fig. 8-b, a T-network can model an iris in rectangular waveguide. The theory developed by Marcuvitz in [22] for iris in a waveguide is used to calculate $X_{a}$ and $X_{b}$. The T-network is then transformed into a $K$-inverter (Fig. 8-c) using (3) and (4) [23].

$$
\begin{gathered}
K=Z_{0}\left|\tan \left(\frac{\phi}{2}\right)+\tan ^{-1} \frac{X_{a}}{Z_{0}}\right| \\
\phi=\tan ^{-1}\left(\frac{2 X_{b}}{Z_{0}}+\frac{X_{a}}{Z_{0}}\right)-\tan ^{-1} \frac{X_{a}}{Z_{0}}
\end{gathered}
$$

Using this model, the filter is designed on the basis of the well-known synthesis techniques for inductive irises in rectangular waveguide. Practically, the lengths and widths of SIW cavities obtained by this procedure will be adjusted a little bit to satisfy the specifications by using a full-wave analysis with HFSS.

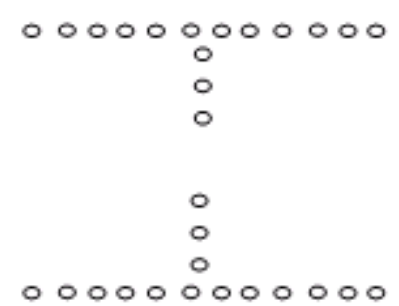

(a)

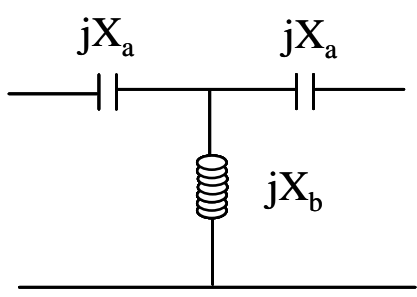

(b)

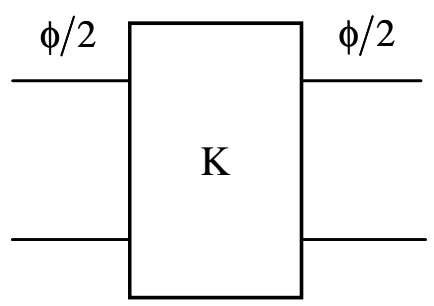

(c)

Fig. 8: Design process of inductive post-wall irises filter. (a) post-wall iris in waveguide. (b) Equivalent T-network. (c) Equivalent $K$-inverter network.

With the model presented, we have designed the $4^{\text {rd }}$-degree SIW filter. We used a $0.8 \mathrm{~mm}$ thick dielectric substrate with a relative permittivity of 4.4 and a loss tangent of 0.015 . Table 2 summarizes the dimensions of the filter after HFSS optimization of the theoretical dimensions.

\begin{tabular}{|c|c|c|c|}
\hline $\mathrm{i}$ & 1 & 2 & 3 \\
\hline $\mathrm{L}_{\mathrm{SIWi}_{\mathrm{i}}}(\mathrm{mm})$ & 6.6 & 13.8 & 15.1 \\
\hline $\mathrm{Wsiw}_{\mathrm{i}}(\mathrm{mm})$ & 11.96 & 9.42 & 8.9 \\
\hline \multicolumn{4}{|c|}{$\mathrm{W}_{\mathrm{m}}=1.4 \mathrm{~mm}, \mathrm{~W}_{\mathrm{t}}=5.82 \mathrm{~mm}, \mathrm{~L}_{\mathrm{t}}=21.6 \mathrm{~mm}$} \\
\hline
\end{tabular}

Tab. 2: Dimensions of SIW inductive-window filter. 
The Photograph of the manufactured SIW filter with stepped transitions is given in Fig. 9.

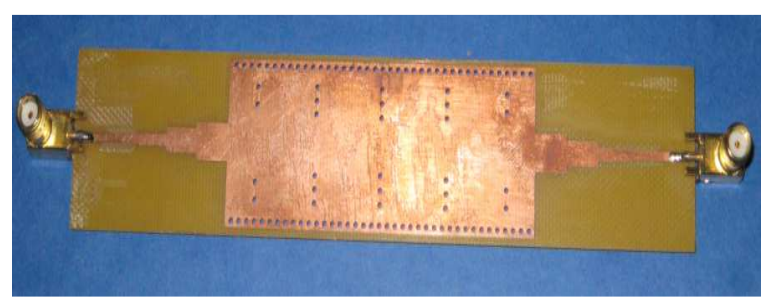

Fig. 9. Photograph of the manufactured SIW inductive filter.

The HFSS and measured reflection and transmission coefficients are shown in Fig. 10.

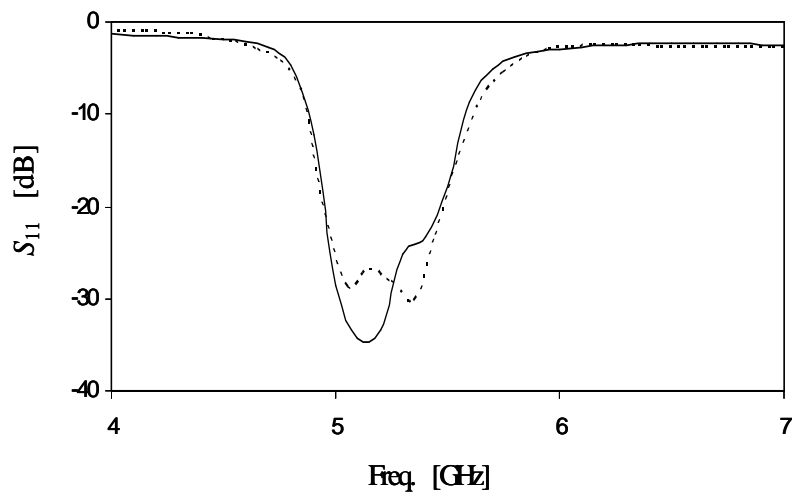

(a)

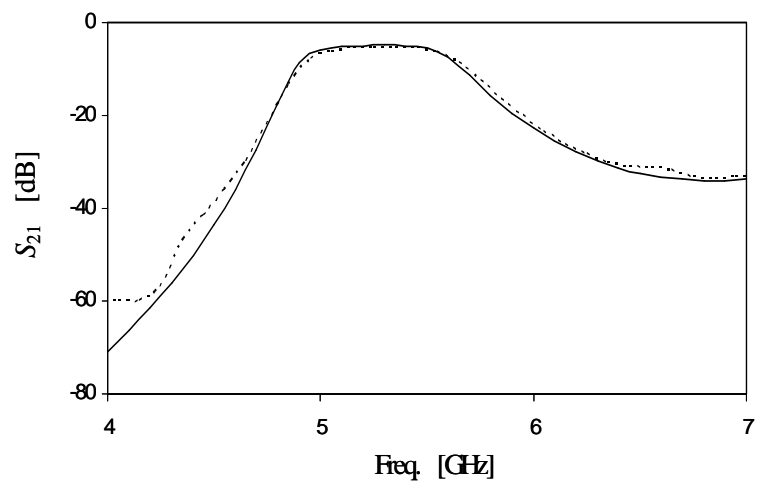

(b)

Fig. 10. Return losses and insertion losses of the SIW inductivewindow filter with post-wall irises a) $\mathrm{S}_{11}$ as a function of frequency. (b) $S_{21}$ as a function of frequency.

(- HFSS Simulation - - Measurement ).

One can note a good agreement between the simulation and measurement results. In the passband, the insertion loss is around $5 \mathrm{~dB}$ and the return loss is less than $25 \mathrm{~dB}$.

\section{Conclusion}

A SIW cavity filter with post-wall irises using a new type microstrip line to SIW transition is proposed and demonstrated around $5 \mathrm{GHz}$. The fabricated $4^{\text {rd }}$ degree filter exhibits an insertion loss of $5 \mathrm{~dB}$ and the return loss is better than $25 \mathrm{~dB}$ in the passband. The proposed filter has small size, low loss, and can be directly integrated with other circuits without any additional mechanical assembling tuning. Additionally, the structure proposed is easily scalable over microwave and millimeter frequency ranges.

\section{References}

1. F. Xu, X. Jiang and Ke Wu, IET Microw. Antennas Propag. 2, 188 (2008)

2. D. Deslandes, Ke Wu, IEEE Trans. Microw. Theory Tech. 51, 593 (2003)

3. W. Che, L. Geng, K. Deng, Y. L. Chow, IEEE Trans. Microw. Theory 56, (2008)

4. Z. C. Hao, W. Hong, J. X. Chen, X. P. Chen, Ke Wu, IEEE Trans. Microw. Theory Tech 53, 2968 (2005)

5. W. Hong, B. Liu, G. Q. Luo, Q. H. Lai, J. F. Xu, Z. C. Hao, F. F. He, X. X. Yin, IEEE International Workshop Antenna Tech., Cambridge, UK, (2007)

6. H. Tang, W. H. Hong, J. Chen, G. Luo, Ke Wu, IEEE Trans. Microw. Theory Tech 55, 776 (2007)

7. A. Suntives, R. Abhari, IEEE Trans. Microw. Wireless Compon. Lett. 17, 697 (2007)

8. Z. C. Hao, W. Hong, X. P. Chen, J. X. Chen, Ke Wu, T. J. Cui, IEEE Microw. Wireless Compon. Lett. 15, 95 (2005)

9. Y. L. Zhang, W. Hong, K. Wu, J. X. Chen, H. J. Tang, IEEE Trans. Microw. Theory Tech 53, 1280 (2005)

10. L. Yan, W. Hong, Ke Wu and T.J. Cui, IEE Proceedings in Microw. Antennas Propag 152, 35 (2005)

11. T-S. Yun, H. Nam, K-B. Kim, J-C. Lee, Proceedings of the AsiaPacific Microwave Conference 1, (2005)

12. X-P. Chen, D. Drolet, $\mathrm{Ke} \mathrm{Wu}$, Proceedings of the Canadian Conference on Electrical and Computer Engineering, 2007 (659)

13. X-P. Chen, Ke Wu, Proceedings of the IEEE MTT-S International Microwave Symposium Digest, 2008 (1231)

14. Y. Cassivi, L. Perregrini, P. Arcioni, M. Bressan, Ke Wu, G. Onciauro, IEEE Microw. Wireless Compon. Lett. 12, 333 ( 2002).

15. Y. Cassivi, L. Perregrini, K. Wu, and G. Conciauro, Proceedings if the Europ. Microw. Conf., Milano, Italy, (2002)

16. B. S. Kim, J. W. Lee, K. S. Kim, M. S. Song, Proceedings of the IEEE MTT-S Microw. Symp. Digest 2, Texas, USA, 1097 (2004)

17. Z. Sotoodeh, F. H. Kashani, H. Ameri, Electromagnetics Research Letters 2, 141 (2008)

18. Y. Lee, Progress In Electromagnetics Research Letters 2, 37 (2008)

19. A. Eldek, Progress In Electromagnetics Research 2, 177 (2008)

20. S. Yin, T. Vasilyeva, P. Pramanick, Intern. J. Microw. Millimeter-Wave Computer-Aided Engineering 8, 484 (Dec. 1998)

21. K. Nouri, M. Feham, Intern. J. Infrared and Millimeter Waves 26, (Jun. 2005)

22. N. Marcuvitz, Waveguide Handbook, (McGraw-Hill, New York, 1951)

23. R. G. L. Matthaei, L. Young, and E. M. T. Jones, Microwave filters, in Impedance-Matching Networks and Coupling Structures, (McGraw-Hill, New York, 1964) 